\title{
Роль Российского респираторного общества в развитии учения о саркоидозе
}

ГОУ ВПО Казанский государственный медицинский университет Росздрава: 420012, Казань, ул. Бутлерова, 49

A.A.Visel, I.Yu.Visel

\section{A role of Russian Respiratory Society in improving our knowledge on sarcoidosis}

Key words: sarcoidosis, Russian medical science, Russian Respiratory Society, Russian National Congress on respiratory diseases.

Ключевые слова: саркоидоз, отечественная медицинская школа, Российское респираторное общество, национальные конгрессы по болезням органов дыхания.

Стремительный рост информации о заболеваниях, их патогенезе и лечении, доступность получения в короткие сроки результатов исследований, проведенных в лабораториях и клиниках разных континентов, требуют постоянного обобщения информации и приведения ее в вид, доступный для врачей, внедряющих достижения современной науки в практику. В то же время укрепление правовой базы здравоохранения, стремление к защите интересов больного и упрощению разрешения споров о качестве, своевременности и правомерности действий медицинских работников стали основой для создания соглашений, клинических рекомендаций и стандартов. Объединением специалистов в области патологии органов дыхания, решающих эти проблемы, ста-

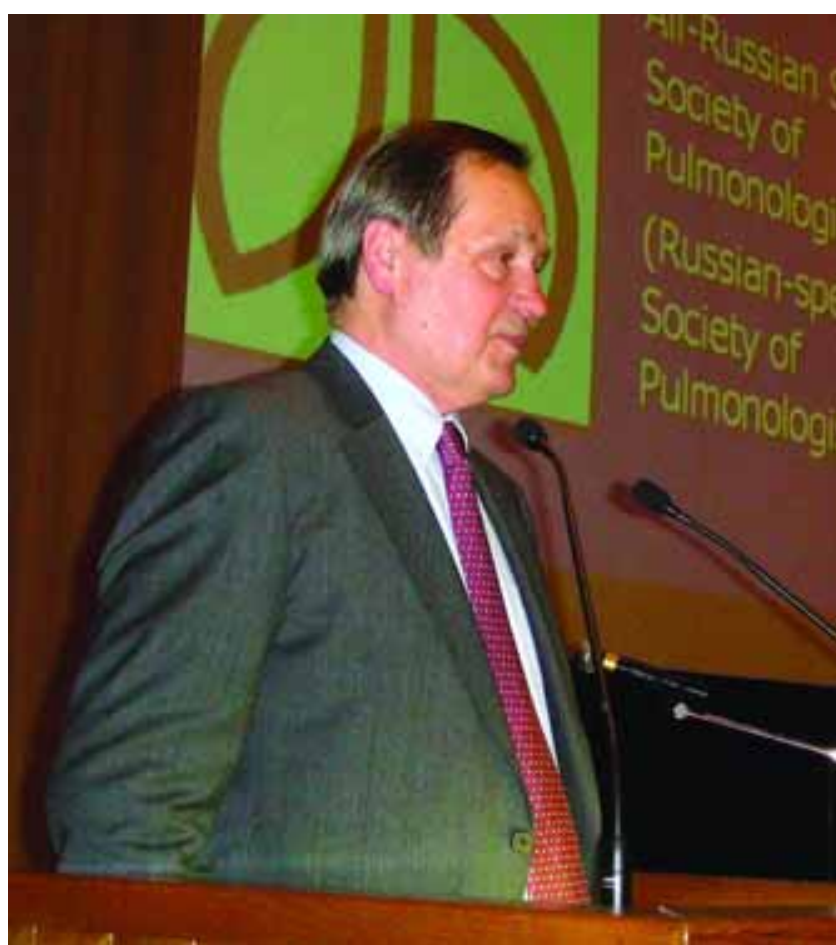

Академик РАМН А.Г.Чучалин во время открытия ХIX Национального конгресса по болезням органов дыхания, Москва, 2009 г. ло Российское респираторное общество (РРО), созданное и ведомое главным терапевтом Российской Федерации академиком РАМН Александром Григорьевичем Чучалиным. За 20 лет существования РРО созданы и постоянно совершенствуются стандарты оказания медицинской помощи больным бронхиальной астмой, хронической обструктивной болезнью легких, внебольничной и нозокомиальной пневмонией. Примером эффективной скоординированной работы экспертов РРО стали события, связанные со случаями пандемического гриппа во 2-й половине 2009 г. Наряду с распространенными заболеваниями и ситуациями, требующими оперативного реагирования, существуют состояния, понимание которых требует мультидисциплинарного подхода. Их этиология до конца не ясна, а лечение направлено на симптомы и отдельные звенья патогенеза. Примером такой патологии является саркоидоз.

Саркоидоз - относительно доброкачественный неказеифицирующийся гранулематоз неясной природы - известен около 130 лет. Понимание этого заболевания во многом зависело от круга специалистов, занимающихся этими больными. В течение нескольких 10-летий саркоидоз изучали дерматологи, такие как Д.Хатчинсон, который в 1869 г. описал поражения кожи у работника угольного причала. Э.А.Бенье в 1889 г. назвал это состояние "ознобленной волчанкой" (lupus pernio), а в 1892 г. М.Теннесон описал эпителиоидно-гигантоклеточный инфильтрат в дерме. В России впервые это состояние представили на заседаниях Московского дерматологического общества Л.Н.Мурзин (1892 г.) и Я.Н.Соколов (1903 г.), а описал в 1910 г. А.А.Боголепов. Термин "саркоидоз" был введен в практику дерматологом Цезарем Питером Беком в 1899 г.

Одно из первых наблюдений саркоидоза органов дыхания (1915 г.) принадлежит пульмонологу Александру Битторфу, который вместе с дерматологом Эрихом Кузницки описалл 27-летнего солдата с множественными кожными и подкожными узлами, гистология которых соответствовала саркоидам Бека, 
а при рентгенологическом исследовании грудной клетки было выявлено расширение корней и изменения в легочной ткани. Первым концепцию саркоидоза как системного заболевания выдвинул шведский дерматолог Йорген Шауман, который в 1916 г. описал больных саркоидозом с множественными локализациями поражения и вовлечением легких, костей, миндалин, селезенки и печени; им же был описан привычный и высокоспецифичный в понимании современных врачей симптом саркоидоза 2-стороннее увеличение лимфатических узлов корней легких. Однако Й.Шауман, как и многие другие ученые того времени, полагал, что саркоидоз является вариантом течения туберкулеза. Это заблуждение доминировало достаточно длительное время и продолжает оказывать влияние на оказание помощи больным саркоидозом в отдельных странах.

Следует заметить, что отечественная медицинская школа более полувека тому назад уже была близка к современному пониманию саркоидоза как неинфекционной патологии. И.А.Кассирский в 1962 г. рассматривал саркоидоз как доброкачественный гранулематоз, а И.В.Давыдовский в 1958 г. - как ретикулоэндотелиоз. В течение 50-60-х гг. ХХ в. саркоидоз был осмыслен как нарушение механизма защиты организма от инородных агентов, микроорганизмов или иных антигенов - гранулематозного воспаления, которое является вариантом хронического воспаления и может быть вызвано нерастворимыми или медленно разрушающимися (персистирующими) агентами. В формировании подобной концепции саркоидоза значительна роль британских исследователей, среди которых наиболее выделяется Д.Д.Джеймс, посвятивший изучению саркоидоза несколько 10-летий.

В России с 50-х гг. XX в. большинство научных школ, занимавшихся проблемами эпидемиологии, диагностики, лечения и наблюдения за больными саркоидозом было связано с противотуберкулезными учреждениями. Трудно переоценить вклад фтизиатрической науки в изучение гранулематозных заболеваний. Морфологическое сходство, выявление значительной доли больных в ходе массовых обследований населения на туберкулез, аналогичные возможные локализации поражения (органы дыхания, периферические лимфатические узлы, кожа, глаза, кости) - все это способствовало поступлению больных саркоидозом в противотуберкулезные учреждения. Тем не менее в знаковой для истории учения о саркоидозе монографии проф. А.Е.Рабухина (написанной совместно с М.Н.Доброхотовой и Н.С.Тонитровой) саркоидоз не был отождествлен с туберкулезом. Существенный вклад в современное понимание этого гранулематоза внесла концепция акад. А.Г.Хоменко о роли микобактерий-ревертантов в патогенезе развития саркоидоза. Стройные схемы наблюдения и лечения саркоидоза были предложены в Московском НИИ туберкулеза (ныне - НИИ фтизиопульмонологии ММА им. И.М.Сеченова). В Ленинграде (ныне - Санкт-Петербург) в начале 60-х гг. прошлого века был создан Городской саркоидозный центр первым заведующим кафедрой туберкулеза

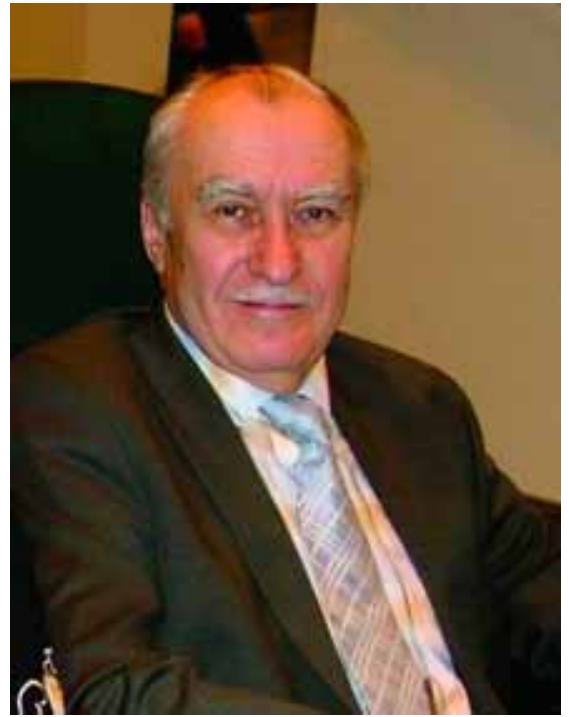

Профессор М.М.Илькович, Москва, 2010 г.

проф. А.Я.Цигельником. Он призывал воздерживаться от назначения кортикостероидной терапии при бессимптомном течении заболевания на ранних его стадиях. Его работу продолжила проф. 3.И.Костина, благодаря ее трудам Городской саркоидозный центр приобрел статус Северо-Западного центра и был создан 1-й Регистр больных саркоидозом легких. Опыт проведения дифференциальной диагностики туберкулеза и саркоидоза, особенно их внелегочных проявлений, позволил сотрудникам НИИ фтизиопульмонологии МЗ и СР РФ (директор - проф. А.В.Васильев, ныне - проф. П.К.Яблонский) разработать четкий алгоритм дифференциальной диагностики этих заболеваний, включая гистологическую верификацию диагноза с применением иммунологических и иммуногистохимических исследований.

Интерес пульмонологов как представителей более молодой специальности к саркоидозу был связан с созданием в 1967 г. Всесоюзного НИИ пульмонологии (ныне НИИ пульмонологии СПбГМУ им. акад. И.П.Павлова). Сотрудники отделения дифференциальной диагностики (руководитель проф. М.М.Илькович, затем - директор НИИ пульмонологии СПбГМУ им. акад. И.П.Павлова), работая в тесном контакте с ведущими лабораториями ВНИИП и подразделениями 1-го ЛМИ, создали уникальный банк данных больных с различными формами интерстициальных заболеваний легких. Опыт Санкт-Петербургской школы пульмонологов был представлен в серии монографий, среди которых "Диссеминированные процессы в легких", "Саркоидоз" и др. На страницах этих книг, ставших руководством к действию для многих практических врачей, достаточно твердо высказывалась позиция о недопустимости пребывания больного саркоидозом, получающего системные глюкокортикостероиды или цитостатики, в противотуберкулезных учреждениях. Заметим, что эта точка зрения была высказана не пульмонологами, а фтизиопедиатрами. Сотрудники Московского НИИ фтизиопульмонологии Л.В.Лебедева и В.Н.Олянишин в 1982 г. предла- 
гали вести учет больных саркоидозом детей в противотуберкулезных диспансерах только в период дифференциальной диагностики (по нулевой группе учета), а затем наблюдать у участкового педиатра, проводя повторные курсы лечения в условиях соматических детских стационаров. Очевидно, что риск пребывания больных (особенно детей!), получающих иммуносупрессивные средства, в противотуберкулезных учреждениях ничем не обоснован.

Появление РPO (изначально - научного общества пульмонологов) в 1990 г. стало знаковым событием. Понимание многих заболеваний и развитие учений о них требовали свободы мысли, дискуссии. Впервые пульмонологи, терапевты, фтизиатры, онкологи и иммунологи получили общую площадку для обсуждения проблем. С 1990 по 2003 гг. на ежегодных Национальных конгрессах по болезням органов дыхания велась дискуссия о понимании саркоидоза, месте наблюдения больных и тактике их лечения. Возникала полемика фтизиатров, с одной стороны, и пульмонологов с терапевтами - с другой. Очень активную позицию занимали пульмонологи, отстаивавшие право больных с доказанным саркоидозом не посещать противотуберкулезные учреждения после исключения туберкулеза на первичном этапе диагностики.

Итогом дискуссии стало исключение больных саркоидозом из сферы наблюдения фтизиатров. Заметим, что это не был императивный приказ по пульмонологической или терапевтической службе, это был приказ, определявший порядок оказания помощи больным туберкулезом в России. Приказ Минздрава РФ № 109 от 21.03.03 не содержал VIII группы диспансерного учета (саркоидоз), ее ликвидация подтверждалась приказом Минздрава РФ № 312 от 14.07.03 "О признании утратившими силу приказов Минздравмедпрома России и Минздрава России № 324 от 22.11.95 и № 33 от 02.02.98". Вывод саркоидоза из-под прямого наблюдения фтизиатров был согласован с переходом от МКБ-9 к МКБ-10. В МКБ-9 саркоидоз имел код 135 и относился к "дру-

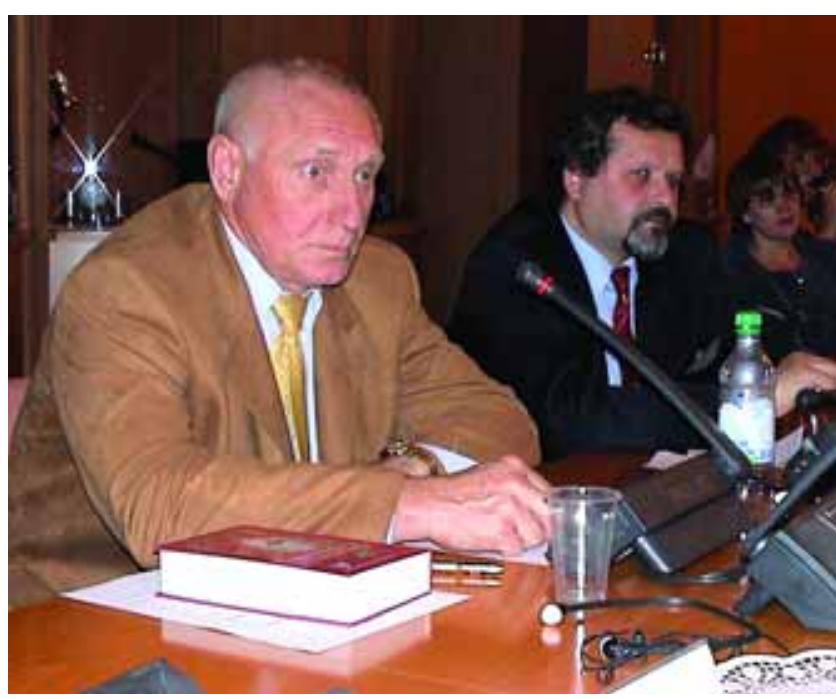

Профессора Е.И.Шмелев и С.Е.Борисов на симпозиуме по саркоидозу во время ХІІІ Национального конгресса, Санкт-Петербург, 2003 г. гим инфекционным и паразитарным болезням" (коды 130-136) среди инфекционных и паразитарных болезней (коды 001-139). В МКБ-10 саркоидоз кодируется как D86 (D86,0-D86,9) и отнесен к III классу "Класс III. Болезни крови, кроветворных органов и отдельные нарушения, вовлекающие иммунный механизм" (коды D50-D89).

Первую статью по саркоидозу в журнале "Пульмонология" опубликовал коллектив московских авторов Е.И.Шмелев, М.Ш.Мацкеплишвили, И.Э.Степанян, В.В.Романов "Плазмаферез в лечении больных саркоидозом органов дыхания" (1991 г., № 3). Вторая работа по саркоидозу была опубликована уже в 1993 г. "Иммунологические и биохимические особенности патогенеза саркоидоза легких и идиопатического фиброзирующего альвеолита", ее авторами были ученые из Санкт-Петербурга: Т.П.Сесь, И.В.Походзей, А.Г.Булычев и Е.А.Леонтьева. Третья публикация (1-я экспериментальная) состоялась в 1-м номере журнала за 2000 г. "Репаративные реакции в легких при лечении экспериментального гранулематоза (саркоидоза)" (авторы: Л.Е.Гедымин, В.В.Ерохин, Л.Н.Лепеха, М.Б.Голант, Д.М.Беляев, Л.З.Балакирева, T.В.Колпикова). В том же номере находим 4-ю работу того же Центрального НИИ туберкулеза РАМН "Особенности течения саркоидоза у больных с персистированием зернистых форм микобактерий" (Л.В.Озерова, С.Г.Сафонова, Н.П.Рыбакова, Л.Г.Гедымин, В.В.Романов, И.П.Зайцева, О.Н.Шеметун). То есть за первые 10 лет существования журнала были опубликованы 4 работы, посвященные непосредственно саркоидозу.

В материалах пульмонологических конгрессов саркоидоз был и остается широко обсуждаемой темой. Так в материалах I Всесоюзного конгресса по болезням органов дыхания мы находим 21 тезис в отдельно выделенном разделе "Саркоидоз". Из них 19 работ были представлены фтизиатрами, 1 - пульмонологом (М.М.Илькович) и 1 - профпатологами.

В 1995 г. тезисы по саркоидозу были размещены в разделах "Диффузные поражения легких" (10 тезисов из 20) и "Интерстициальные заболевания легких" (11 из 33). Работы были представлены фтизиатрами, пульмонологами и терапевтами.

В 2000 г., в материалах Х Национального конгресса по болезням органов дыхания саркоидоз оставался в разделе "Интерстициальные заболевания легких" и был представлен 12 работами фтизиатров, пульмонологов и аллергологов-иммунологов из 29 опубликованных тезисов.

Материалы XV Национального конгресса по болезням органов дыхания имели отдельный раздел "Саркоидоз" (13 тезисов, из них 12 - от фтизиатров). Из 15 тезисов раздела "Интерстициальные заболевания легких" 4 затрагивали проблемы саркоидоза, их авторами были пульмонологи и торакальные хирурги.

Последний XIX Национальный конгресс, прошедший в Москве, также содержал отдельный блок из 15 тезисов, посвященных саркоидозу. Только 3 из них подготовили фтизиатры, а остальные - пульмонологи, терапевты, торакальные хирурги и онкологи. 
На этом конгрессе прошла школа по саркоидозу, а симпозиум по этому гранулематозу возглавил известный терапевт акад. РАМН А.Н.Мухин.

Материалы конгрессов и публикации в журнале свидетельствуют о явном смещении интереса к саркоидозу от фтизиатрии к пульмонологии и терапии.

На конгрессах и в публикациях РРО наиболее часто тему саркоидоза представляли Евгений Иванович Шмелев (Москва), Михаил Михайлович Илькович (Санкт-Петербург), Сергей Евгеньевич Борисов (Москва), Игорь Эмильевич Степанян (Москва), Владимир Викторович Романов (Москва), а в последнее 10-летие также Александр Андреевич Визель (Казань) и Елена Николаевна Попова (Москва).

Саркоидоз - лишь частный случай, пример, когда коллективное мышление ученых, объединенных в РРО, позволило достичь консенсуса. Итогом многолетнего изучения и обсуждения проблемы стала монография РРО - 3-я в фундаментальной серии РРО, редактируемой акад. РАМН А.Г.Чучалиным, посвященная саркоидозу. Этот труд может стать отправ- ной точкой для дальнейшего совершенствования изучения саркоидоза как полиорганной патологии научными коллективами, состоящими из ученых разных специальностей. Наиболее перспективны исследования саркоидоза на уровне генома человека, молекулярной генетики и фундаментальной иммунологии. В клинике наиболее актуален вопрос отдаленного прогноза у больных, получавших разные виды лечения, выявления достоверных маркеров спонтанной ремиссии. Последующие конгрессы станут ареной для обсуждения этих исследований. Пусть пока мы далеки от решения проблемы саркоидоза, но свет в конце туннеля уже забрезжил!

\section{Информация об авторах}

Визель Александр Андреевич - д. м. н., проф., зав. кафедрой фтизиопульмонологии Казанского государственного медицинского университета; тел.: (843) 276-16-61; e-mail: lordara@inbox.ru

Визель Ирина Юрьевна - к. м. н., ассистент кафедры фтизиопульмонологии Казанского государственного медицинского университета; тел.: (843) 276-16-61; e-mail: tatpulmo@mail.ru УДК 616.24-002.28 